\title{
Metazoan Maelstrom is an RNA-binding protein that has evolved from an ancient nuclease active in protists
}

\author{
KUAN-MING CHEN, ${ }^{1,2,3}$ EDGAR CAMPBELL, ${ }^{1,2,3}$ RADHA RAMAN PANDEY, $^{1,2}$ ZHAOLIN YANG, $^{1,2}$ \\ ANDREW A. MCCARTHY, ${ }^{1,2}$ and RAMESH S. PILLAI ${ }^{1,2}$ \\ ${ }^{1}$ European Molecular Biology Laboratory, Grenoble Outstation, 38042 Grenoble Cedex 9, France \\ ${ }^{2}$ Unit for Virus Host-Cell Interactions, University Grenoble Alpes-EMBL-CNRS, 38042 Grenoble Cedex 9, France
}

\begin{abstract}
Piwi-interacting RNAs (piRNAs) guide Piwi argonautes to their transposon targets for silencing. The highly conserved protein Maelstrom is linked to both piRNA biogenesis and effector roles in this pathway. One defining feature of Maelstrom is the predicted MAEL domain of unknown molecular function. Here, we present the first crystal structure of the MAEL domain from Bombyx Maelstrom, which reveals a nuclease fold. The overall architecture resembles that found in $\mathrm{Mg}^{2+}-\mathrm{or}^{2+} \mathrm{n}^{2+}-\mathrm{dependent}$ DEDD nucleases, but a clear distinguishing feature is the presence of a structural $\mathrm{Zn}^{2+}$ ion coordinated by the conserved ECHC residues. Strikingly, metazoan Maelstrom orthologs across the animal kingdom lack the catalytic DEDD residues, and as we show for Bombyx Maelstrom are inactive as nucleases. However, a MAEL domain-containing protein from amoeba having both sequence motifs (DEDD and ECHC) is robustly active as an exoribonuclease. Finally, we show that the MAEL domain of Bombyx Maelstrom displays a strong affinity for single-stranded RNAs. Our studies suggest that the ancient MAEL nuclease domain evolved to function as an RNA-binding module in metazoan Maelstrom.
\end{abstract}

Keywords: MAEL; piRNA; EHI_192630; ribonuclease; Bombyx; E. histolytica; Piwi

\section{INTRODUCTION}

Mobile genetic elements like transposons have successfully colonized a substantial portion of eukaryotic genomes. Approximately $45 \%$ of the human genome can be directly traced back to their origin from transposable elements. While most of these are broken inactive repetitive sequences, some are full-length copies that encode proteins facilitating their mobility within the genome. Their insertion into new locations can cause mutations and promote ectopic recombination events that threaten genome integrity. Germlines are tasked with the job of faithfully transmitting genetic information from one generation to the next and this makes them particularly sensitive to any transposition events. Chromatin and DNA modifications stably silence transposons in the genome, but epigenetic upheavals that accompany germ cell development have the potential to release them from this repression (Malone and Hannon 2009). To guard against transposon activity, animal gonads have evolved a dedicated small RNA-based transposon defense system that uses Argonaute proteins of the Piwi clade and their associated 24-31 nucle-

\footnotetext{
${ }^{3}$ These authors contributed equally to this work.

Corresponding authors: andrewmc@embl.fr, pillai@embl.fr

Article published online ahead of print. Article and publication date are at http://www.rnajournal.org/cgi/doi/10.1261/rna.049437.114. Freely available online through the RNA Open Access option.
}

otide (nt) Piwi-interacting RNAs (piRNAs) (Ghildiyal and Zamore 2009).

Consistent with their role in transposon silencing, piRNAs bear sequence complementarity to host transposon sequences. This allows piRNAs to guide Piwi proteins to their nucleic acid targets. In the cytoplasm, Piwi endonucleases (slicers) destroy transposon transcripts, while nuclear Piwi complexes specify chromatin or DNA modifications to prevent transcription from target transposon genomic loci. Information on which genomic elements are to be targeted is contained in discrete genomic loci called piRNA clusters. These clusters are $\sim 50-150 \mathrm{~kb}$ in length and hold a diverse array of transposon fragments representing all transposable elements in the host genome. Long single-stranded cluster transcripts are converted into tens of thousands of primary piRNAs that provide germ cells with an arsenal to target every transposon in the genome. Germ cells also possess a mechanism to amplify those silencing molecules that are most useful at any given point in time. The initiator of such an amplification process is the endonucleolytic cleavage of a target transposon transcript by a Piwi protein. After this, one of the Piwigenerated cleavage fragments gets loaded into a new Piwi protein to mature as a (sense-oriented) secondary piRNA.

(C) 2015 Chen et al. This article, published in $R N A$, is available under a Creative Commons License (Attribution 4.0 International), as described at http://creativecommons.org/licenses/by/4.0/. 
Secondary piRNA biogenesis in the Bombyx mori (Silkworm) ovary-derived BmN4 cell cultures (Kawaoka et al. 2009) is mediated by an ATP-dependent piRNA Amplifier complex assembled on transposon targets by the DEAD box RNA helicase Vasa. This complex facilitates transfer of a cleavage fragment between the two Piwi proteins (from Siwi to Ago3) expressed in these cells (Xiol et al. 2014). Such secondary piRNAs then guide cleavage of complementary sequences (for example, in long cluster transcripts) to generate the exact same antisense piRNA that initiated the whole process. This adaptive piRNA amplification process called the pingpong cycle generates more silencing molecules every time target transposons are cleaved (Brennecke et al. 2007). Most known piRNA biogenesis factors are enriched in perinuclear, cytoplasmic granules called nuage, and these are also thought to be major centers of piRNA action (Lim and Kai 2007). So piRNA precursors and transposon targets have to meet up with the pathway factors within these germline granules.

Genetic screens and biochemical studies have uncovered a wealth of factors that are necessary for piRNA biogenesis and transposon silencing in both the fly and mouse models. Maelstrom (Findley et al. 2003) was originally identified as a member of the spindle-class mutants that display female sterility and patterning defects in the developing fly oocyte. Maelstrom is a steady-state resident of the nuage, but it is unique in being a nucleo-cytoplasmic shuttling protein (Findley et al. 2003). Subsequent studies linked Maelstrom to retrotransposon control in the fly germline (Lim and Kai 2007), a role that is also conserved in mice (Soper et al. 2008). Given the role in transposon control and subcellular localization with other piRNA biogenesis factors in the fly and mouse nuage, Maelstrom was linked to a possible role in the piRNA pathway.

Transcriptional silencing in the Drosophila ovarian cells is mediated by the prototypic Piwi clade member, Piwi, which promotes deposition of $\mathrm{H} 3 \mathrm{~K} 9 \mathrm{me} 3$ on transposon sequences. Analysis of piRNA levels in fly mael mutant ovaries revealed no impact on piRNA biogenesis (Sienski et al. 2012). Given that the nuclear function of Piwi is independent of Maelstrom, the protein was proposed to play a silencing effector role in an unknown step downstream from chromatin methylation (Sienski et al. 2012). Any such role linked to chromatin may not be conserved as Maelstrom is also expressed in the Bombyx BmN4 cells that clearly lack a nuclear Piwi pathway (Xiol et al. 2014). Furthermore, Maelstrom is shown to associate with components of the microtubule-organizing center (MTOC) (Sato et al. 2011) and transcriptionally repress microRNA-7 in fly ovaries (Pek et al. 2009). Finally, in the mouse male germline Maelstrom binds primary piRNA precursors and Piwi proteins, and mael mutants display reduced piRNA levels, indicating a role in piRNA biogenesis (Castaneda et al. 2014). All these genetic studies point to multiple roles for a protein that still remains poorly understood biochemically.

\section{RESULTS}

\section{Crystal structure of the MAEL domain of Bombyx Maelstrom}

Maelstrom is composed of an amino-terminal High Mobility Group (HMG) box and a predicted carboxy-terminal MAEL domain that is a signature feature of the protein across the animal kingdom (Fig. 1A; Zhang et al. 2008). The HMG box is shown to confer DNA-binding to proteins harboring it in other contexts (Bianchi and Agresti 2005). In contrast, information on the biochemical properties and structure of the MAEL domain is not available. To explore this, we crystallized a fragment of Bombyx Maelstrom (BmMael) (see Materials and Methods) containing the MAEL domain. This reveals an $\alpha / \beta$ structure (Fig. 1A) composed of an amino-terminal linker helix followed by the MAEL domain. The linker helix $\alpha_{4}$ (colored in orange) connects the MAEL domain to the amino-terminal HMG box, which in human Maelstrom is made of three helices (RIKEN Structural Genomics/Proteomics Initiative). The MAEL domain (Fig. 1A) is composed of a central $\beta$-sheet composed of five strands $\left(\beta_{1}-\beta_{5}\right)$, where $\beta_{2}$ is antiparallel to the others. The $\beta$-sheet is flanked on one face by three helices $\left(\alpha_{8}-\alpha_{10}\right)$ and on the other by two helices $\left(a_{6}\right.$ and $\alpha_{7}$ ). The bottom of the sheet is capped by helix $\alpha_{5}$. This basic configuration is strikingly similar to that found in DEDD family nucleases, as represented by the $\varepsilon$-subunit of Escherichia coli polymerase III (PDB: 1J53) (Hamdan et al. 2002), which can be superimposed with a RMSD of $1.6 \AA$ for 74 of a possible $174 \mathrm{C} a$ atoms (Fig. 1B).

Despite this overall resemblance between MAEL and DEDD nuclease domains, one striking difference is the presence of a $\mathrm{Zn}^{2+}$ ion in the MAEL structure that bridges the bottom of the $\beta$-sheet and the loop connecting $\alpha_{9}$ and $\alpha_{10}$, which encompasses $\eta_{2}$ (Fig. 1A,C). The $\mathrm{Zn}^{2+}$ ion is tetrahedrally coordinated by E137 from $\beta_{2}, \mathrm{H} 293$ from $\eta_{2}$, and residues C290 and C302 from loops (Fig. 1C). The fact that the $\mathrm{Zn}^{2+}$ ion was captured from the bacterial culture media, and not added during initial crystallization trials, points to its paramount importance for the structural integrity of the MAEL domain. Mutational studies in Drosophila Maelstrom also support such a structural role for the $\mathrm{Zn}^{2+}$ ion, as single point mutations in the conserved ECHC motif of Drosophila Maelstrom (E131A and H291A), identical to E137 and H293 in Bombyx, abrogate its ability to complement mutant flies for transposon silencing and fertility (Sienski et al. 2012). Interestingly, these Drosophila mutants fail to enter the nucleus, pointing to a structural collapse of the protein (Sienski et al. 2012). Thus, our structure reveals that the MAEL domain takes up a unique nuclease fold embellished with a new $\mathrm{Zn}$ binding motif (ECHC).

\section{Metazoan MAEL domain is inactive while that of protists have ribonuclease activity}

A closer comparison of the Bombyx MAEL domain with the DEDD nuclease domain in E. coli Pol III reveals that the 
A
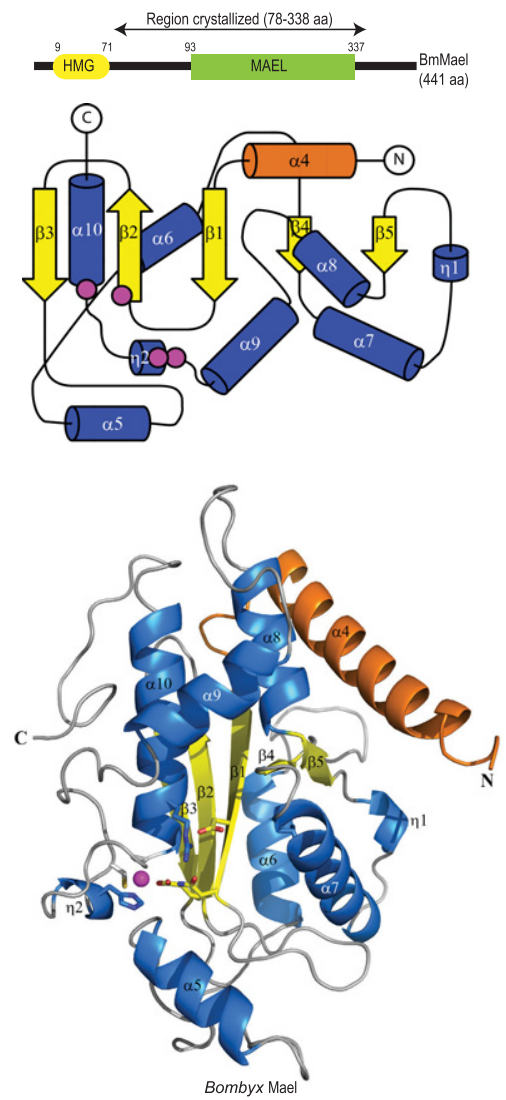

C

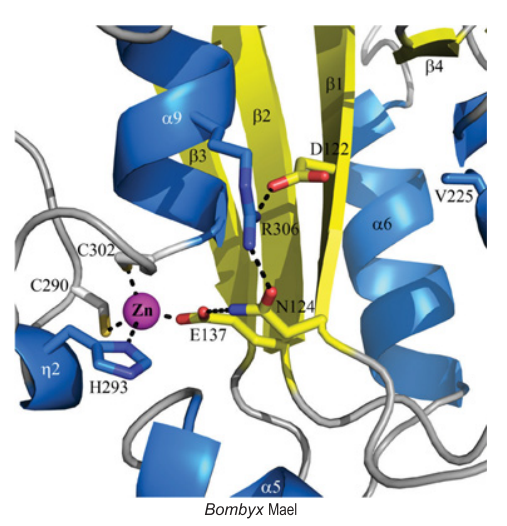

B
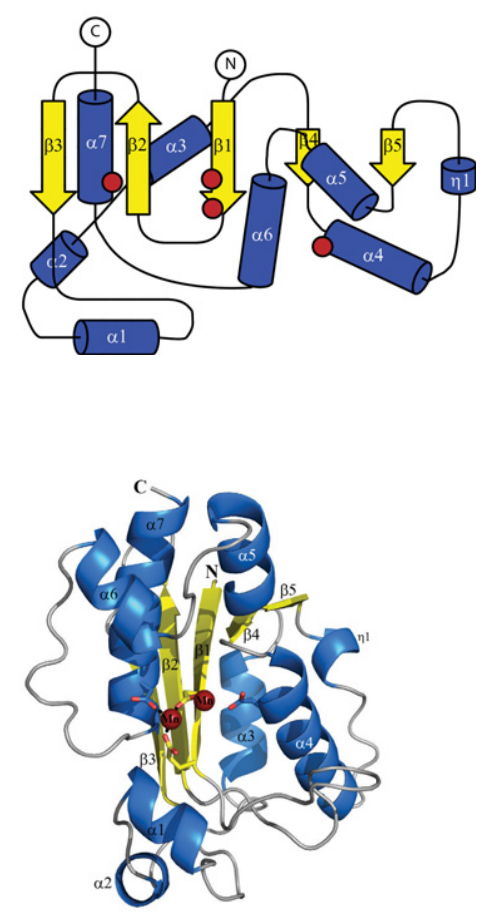

$\xi$ subunit of E. coli Pol III

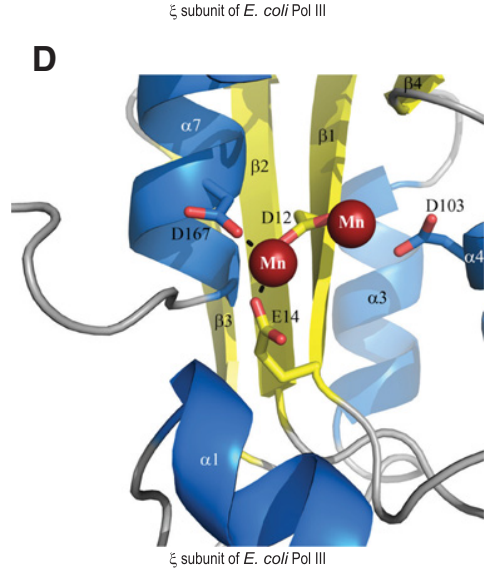

FIGURE 1. The MAEL domain of Bombyx Maelstrom reveals a nuclease fold. (A) A cartoon showing the domain architecture of Bombyx mori Maelstrom (BmMael) indicating the High Mobility Group (HMG) box and the MAEL domain specific to Maelstrom. Structural topology representation of the crystal structure shown below: Helices as cylinders (blue or orange) and $\beta$-strands as arrows (yellow) are shown. Crystal structure of the MAEL domain from BmMael. The amino-terminal linker helix in BmMael connecting the MAEL domain to HMG is colored in orange. (B) Structure of the DnaQ nuclease domain from the $\varepsilon$ subunit of E. coli Pol III (PDB: 1J53). (C) Zoomed view highlighting the residues coordinating the structural $\mathrm{Zn}^{2+}$ ion in MAEL. Note the absence of catalytic residues (DEDD) in the MAEL domain that are essential for nuclease activity in $(D)$ the DnaQ domain. Dotted black lines indicate hydrogen bond interactions.

catalytic residues (D12, E14, D103, and D167) essential for coordinating two $\mathrm{Mn}^{2+}$ ions in the bacterial enzyme are not conserved in the MAEL domain (Fig. 1D). Only the first residue of the DEDD motif (D122 from $\beta_{1}$ ) is conserved in

the Bombyx MAEL domain. All the other residues are replaced by those $(\mathrm{N} 124$ and R306) that preclude any ability in coordinating divalent metal ions. Intriguingly, an extensive hydrogen bonding network links these inactive residues in the catalytic pocket: $\mathrm{N} 124$ from $\beta_{1}$ forms hydrogen bonds (dotted black line in figure) with both E137 of the ECHC motif and R306 from $\alpha_{9}$, while R306 has an additional interaction with D122 from $\beta_{1}$ (Fig. 1C). Furthermore, the $\alpha_{1}$ in the Pol III structure is more proximal to the catalytic residues than $\alpha_{5}$ in the MAEL structure, making the catalytic pocket in the DEDD nuclease marginally more compact when compared with MAEL.

To directly test the catalytic potential of the Bombyx MAEL domain, we incubated the recombinant full-length BmMael protein with a $5^{\prime}$-end labeled single-stranded RNA (ssRNA) (Fig. 2A). As shown in Figure 2B, over $1 \mathrm{~h}$ of incubation at $27^{\circ} \mathrm{C}$ did not yield any cleavage products. Addition of three different metal ions did not change this situation. The MAEL domain is also detected in protists (Zhang et al. 2008), where the catalytic residues DEDD are retained along with the MAEL-specific ECHC motif (Fig. 2C). To test whether the protist MAEL domain harbors nuclease activity, we produced a recombinant version of the MAEL domain-containing protein (EHI_192630) from the human parasitic protozoan Entamoeba histolytica virulent strain HM-1:IMSS (Fig. 2A). Incubation of the protein (EhMael) alone with a ssRNA did not result in its degradation, while addition of $\mathrm{Mg}^{2+}$ or $\mathrm{Mn}^{2+}$ resulted in complete elimination of the input RNA and appearance of a ladder of RNA degradation fragments (Fig. 2B,D). Specificity of the reaction is indicated by the fact that the nuclease activity was inhibited by incubation with the $\mathrm{Mg}^{2+}$-chelating agent EDTA. Use of $\mathrm{Ca}^{2+}$ did not result in any activity (Fig. 2B). These results suggest that the MAEL domain confers ribonuclease activity in protists where the catalytic DEDD residues are preserved, while metazoan Maelstrom proteins (including Bombyx and Drosophila) lack these (Fig. 2C), and are hence inactive. 
A

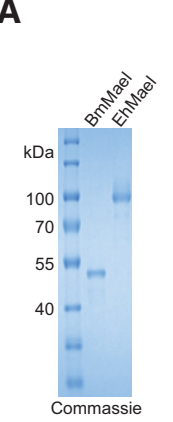

B

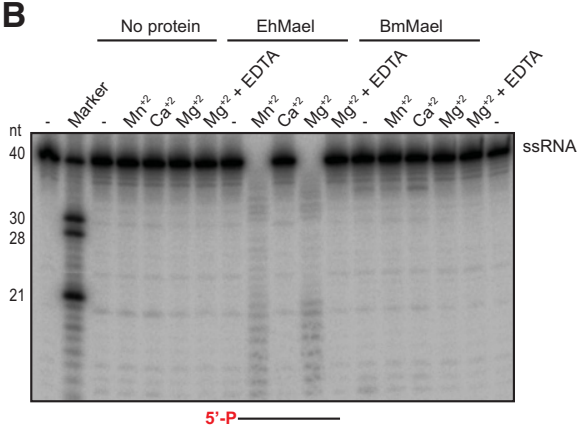

C

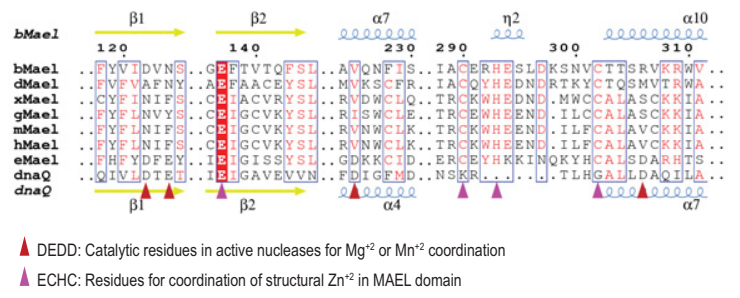

D

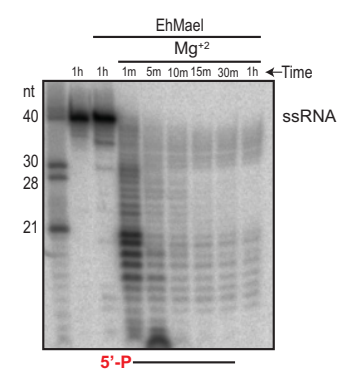

FIGURE 2. Bombyx Maelstrom is inactive as a nuclease but activity is retained in its protist ortholog. (A) Instant Blue staining of recombinant BmMael and E. histolytica MAEL domain (EhMael) proteins used for nuclease assay. (B) Nuclease activity of proteins tested on a single-stranded RNA (ssRNA). Reactions were incubated for $1 \mathrm{~h}$ with indicated proteins in the absence (-) or presence of different metal ions. In reactions containing EhMael and appropriate metal ions $\left(\mathrm{Mn}^{2+}\right.$ and $\left.\mathrm{Mg}^{2+}\right)$ the input ssRNA was completely degraded and appears as a RNA ladder. Note the complete absence of such an activity with BmMael. (C) Selected regions from a sequence alignment of the MAEL domain from Bombyx (b), Drosophila (d), Xenopus (x), Gallus (g), mouse (m), human (h), and E. histolytica (e) Maelstrom proteins. DnaQ is the nuclease domain from the $\varepsilon$ subunit of E. coli Pol III. The secondary structure elements: $\alpha$-helices, $3_{10}$ helices $(\eta)$, and $\beta$-strands are shown above (for BmMael) and below (for DnaQ from Pol III; PDB: 1J53) the alignment. The arrowheads indicate conserved residues required for catalytic activity (red) and $\mathrm{Zn}^{2+}$ coordination (magenta). (D) A time-course of nuclease activity with EhMael. Time in minutes (min) or hours (h) is indicated.

\section{Metazoan MAEL domain functions as an RNA-binding module}

Since the Bombyx MAEL domain has the core nuclease architecture conserved we tested if it might allow binding to RNA substrates. We examined this with a fluorescently labeled ssRNA and measured decreased fluorescence intensity as readout of protein binding (Fig. 3A). This indicated 216.7 $\pm 75.57 \mathrm{nM}$ binding affinity for full-length BmMael. Interestingly, the construct lacking the HMG box (containing only the linker helix plus the MAEL domain) also showed robust affinity for RNA $(129.9 \pm 18.86 \mathrm{nM})$. Examination of charge distribution on the MAEL domain did not indicate a clear positively charged surface for RNA binding (Fig. 3B). It is therefore likely that the RNA is contacted at a location close to the inactive catalytic pocket. The HMG box may also contribute to nucleic acid binding, and mutants lacking this domain are nonfunctional in vivo (Sienski et al. 2012).

\section{CONCLUSIONS}

Taken together, our study provides structural and biochemical insights into the MAEL domain that is a signature feature of Maelstrom. We show that the MAEL domain is active as a nuclease in protists, while inactive in metazoans, as in the case of Bombyx. We show that the Bombyx MAEL can func- tion as an RNA-binding module and that this activity might be further supported by the HMG box, a known nucleic acid binding domain (Fig. 3C). Since Drosophila and mouse Maelstrom proteins also lack the DEDD catalytic residues (Fig. 2C), we propose that the functions genetically attributed to the protein can only be explained by this RNA-binding activity. In the case of Drosophia germline, Maelstrom might bind transposon transcripts arising from genomic loci undergoing Piwi-mediated transcriptional gene silencing (TGS) (Sienski et al. 2012) and evacuate them to cytoplasmic nuage, where it is delivered to general RNA degradation enzymes for post-transcriptional gene silencing (trans-PTGS) (Fig. 3D). Similarly, in the case of the mouse male germline, Maelstrom is shown to directly bind pachytene piRNA precursors (Castaneda et al. 2014). Since mouse Maelstrom is shown to interact with piRNA pathway factors, it might deliver the precursor RNAs to the processing machinery for generation of pachytene piRNAs (Castaneda et al. 2014). In the case of BmN4 cells, mass spectrometry analysis of HA-Maelstrom complexes also identified associations with piRNA biogenesis factors (data not shown). Thus, the ancient MAEL nuclease domain, after acquiring mutations, was requisitioned into an RNA-binding role in the metazoan piRNA pathway. It is also possible that the MAEL domain in Maelstrom may provide a protein interaction surface for other factors that facilitate its function in the piRNA pathway. 
A

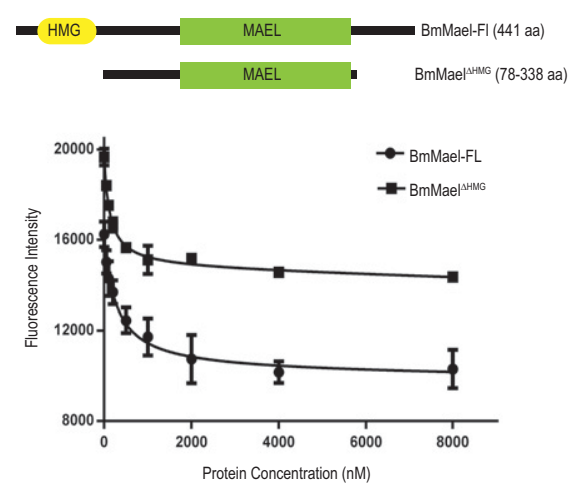

C

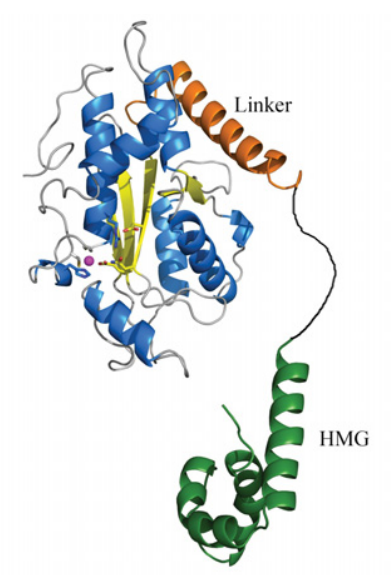

B

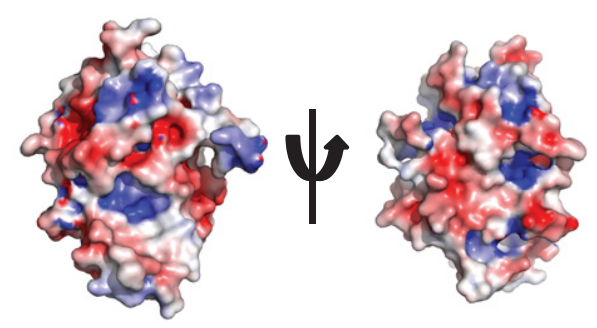

D

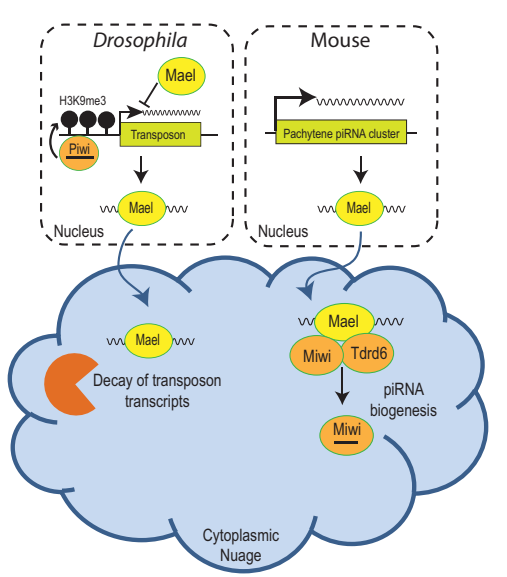

FIGURE 3. Bombyx Maelstrom is an RNA-binding protein. (A) Cartoon showing BmMael constructs used for RNA-binding studies. Fluorescence emission measurements (three independent experiments) using a RNA molecule labeled with a fluorophore and the BmMael proteins are indicated. (B) Surface charge representation of MAEL domain from BmMael contoured from $-6 \mathrm{kTe}^{-1}$ (red) to $+6 \mathrm{kTe}^{-1}$ (blue) generated using PyMOL APBS tools. (C) A composite structural model of Maelstrom created using the MAEL domain of Bombyx Mael and the HMG box domain of human Mael (PDB: 2CTO). (D) A model for Maelstrom's role in the piRNA pathway in the female Drosophila and male mouse germline.

\section{MATERIALS AND METHODS}

\section{Clones and constructs}

The complementary DNA (cDNA) encoding Bombyx mori (Silkworm) Maelstrom (Mael) was isolated from total RNA of BmN4 ovarian cell cultures by reverse-transcription PCR (RT-PCR). The cDNA for MAEL domain-containing protein (EHI_192630) from the human parasitic protozoan Entamoeba histolytica virulent strain HM-1:IMSS was chemically synthesized (Shanghai ShineGene Molecular Biotech, Inc.) using available sequence information (XM_ 648799.2). The full-length proteins were expressed as amino-terminal 6xHis-Sumo tag fusions in either E. coli (for BmMael) or in Spodoptera frugiperda 21 (Sf21) insect cell cultures (for EhMael) using recombinant baculovirus preparations.

The full-length BmMael protein was subjected to limited proteolysis using trypsin protease and the boundaries of stable fragments were defined by peptide mass fingerprinting using MALDI (Proteomics Core Facility, EMBL). All BmMael constructs were expressed from the bacterial expression vector (pETM-11Sumo vector; EMBL Protein Expression and Purification Core Facility) as 6xHis-SUMO-TEVsite-fusions: $28-350$ aa, 78-350 aa, 115-350 aa, 78-338 aa. The construct carrying the amino-terminal linker he- lix and carboxy-terminal MAEL domain (78-338 aa) was crystallized and used in this study.

The full-length EhMael was cloned into the pACEBac2Sumo acceptor vector for expression as a 6xHis-SUMO fusion in the Spodoptera frugiperda 21 (Sf21) insect cell line.

\section{Maelstrom purification}

The Bombyx Mael constructs were transformed into the E. coli Rosetta strain and grown overnight at $16^{\circ} \mathrm{C}$. Cells were lysed $(25$ $\mathrm{mM}$ Tris [pH 8.0], $150 \mathrm{mM} \mathrm{NaCl}, 20 \mathrm{mM}$ Imidazole, $0.5 \%$ Tween 20, 5mM $\beta$-mercaptoethanol, and Protease Inhibitor [Roche]) and His-tagged proteins were purified over Ni-NTA beads. After removal of the 6xHis-Sumo tag by overnight TEV cleavage, the untagged recombinant protein was further purified over an ionexchange column: Q-column (GE Health) for BmMael (78-338 a) or SP-column for full-length BmMael. Fractions containing the recombinant proteins were further purified by size-exclusion chromatography (S75 or S200). Highly pure fractions from this last step were used for crystallography, biophysical measurements, and nuclease assays. The 6xHis-Sumo-EhMael was similarly purified, except that the tag was not removed. 


\section{Crystallization, data collection, and structure solution of Bombyx Maelstrom}

Crystals of native and SeMet substituted protein were grown in hanging drops at $4^{\circ} \mathrm{C}$ using solutions containing $25 \mathrm{mM}$ HEPES ( $\mathrm{pH}$ 7.0), $150 \mathrm{mM} \mathrm{NaCl}, 50 \mu \mathrm{M} \mathrm{ZnCl}_{2}$, and $10 \mathrm{mM}$ DTT. Crystals of the native protein appeared as small needles after $7 \mathrm{~d}$ and were further improved using micro and macro seeding techniques. The SeMet protein typically produced rhombohedral shaped crystals. The native and SeMet crystals were flash frozen at $100 \mathrm{~K}$ after transferring them to identical crystallization conditions containing $20 \%$ glycerol. The SeMet protein crystallized in space group R32 and contained three molecules in the asymmetric unit. A highly redundant 3.4 $\AA$ SeMet anomalous data set was collected at the peak and inflection of the Se-Met signal, as measured by X-ray fluorescence for experimental phasing on ID23-1 (Nurizzo et al. 2006) at the European Synchrotron Radiation Facility (ESRF). The native protein crystallized in space group P21, contained four molecules in the asymmetric unit and a data set to $2.4 \AA$ was obtained using the helical data collection procedure on ID29 at the ESRF (de Sanctis et al. 2012). Integration and scaling was carried out with the XDS suite (Kabsch 2010) and SCALA (Evans 2006), respectively. A summary of the data statistics is given in Table 1 . The resolution cut off was chosen to ensure a I/ $\sigma(I)>1.0$ and a CC $(1 / 2)>50 \%$. We note that sedimentation velocity experiments reveal that Maelstrom does not oligomerize and is monomeric in solution (data not shown).

For the structural solution 14 Se-Met sites were located on the basis of their anomalous differences using SHELXC/D/E (Sheldrick 2010). These sites were refined and experimental phases to $3.4 \AA$ were calculated using the multiple anomalous dispersion (MAD) procedure in autoSHARP. These phases were further improved using Crank2 (Skubak and Pannu 2013), incorporating model building and refinement with Buccaneer (Cowtan 2006) and REFMAC5 (Murshudov et al. 2011). The initial model produced was positioned in the native data set with Phaser (McCoy et al. 2007). The native data set was determined to have pseudomerohedral twinning so all subsequent refinement cycles were performed using REFMAC (Murshudov et al. 2011) or Phenix (Afonine et al. 2012) with

TABLE 1. Crystallographic data collection and refinement statistics

\begin{tabular}{|c|c|c|}
\hline Crystal parameters & Se derivative & Native \\
\hline \multicolumn{3}{|l|}{ Data collection } \\
\hline Wavelength $(\AA)$ & 0.9793 & 0.9537 \\
\hline Space group & R32 & $\mathrm{P} 2_{1}$ \\
\hline Cell dimensions $a, b, c(\AA)$ & $110.3,110.3,622.2\left(\gamma=120^{\circ}\right)$ & $75.4,101.2,101.6\left(\beta=90.04^{\circ}\right)$ \\
\hline $\begin{array}{l}\text { Molecules per asymmetric } \\
\text { unit }\end{array}$ & 3 & 4 \\
\hline Resolution (Å) (final shell) & $50.0-3.4(3.6-3.4)$ & $50.0-2.4(2.5-2.4)$ \\
\hline Observed reflections & 165,670 & 207,711 \\
\hline Unique reflections & 20,625 & 58,899 \\
\hline $\begin{array}{l}\text { Completeness (\%) (final } \\
\text { shell) }\end{array}$ & $99.8(99.1)$ & $98.7(97.9)$ \\
\hline$R_{\text {pim }}(\%)($ final shell $)$ & $5.2(37.9)$ & $7.9(60.1)$ \\
\hline$<I / \sigma(I)>($ final shell $)$ & $10.1(2.0)$ & $5.8(1.2)$ \\
\hline \multicolumn{3}{|l|}{ Model quality indicators } \\
\hline FOM (centric/acentric) & $0.09 / 0.25$ & \\
\hline$R_{\text {cryst }}(\%) / R_{\text {free }}(\%)$ & & $22.7 / 26.4$ \\
\hline RMSD, bonds $(\AA) /$ angles $\left({ }^{\circ}\right)$ & & $0.01 / 1.6$ \\
\hline
\end{tabular}

NCS restraints and twinning options enabled. Model building was carried out with Coot (Emsley et al. 2010) and the stereochemical quality of the protein molecules were validated with Molprobity (Chen et al. 2010). All the crystallographic information is summarized in Table 1 and the crystallographic coordinates have been deposited within the Protein Data Bank (PDB: 5AF0).

\section{Nuclease assays}

Highly purified protein preparations (Ni-affinity column, ion exchange, and gel-filtration) were incubated at $1.0 \mu \mathrm{M}$ concentrations with a $5^{\prime}$-end radiolabeled single-stranded 40-nucleotide RNA in the reaction buffer (25 mM Tris- $\mathrm{HCl}$ [pH 7.5], $150 \mathrm{mM} \mathrm{NaCl}, 2 \mathrm{mM}$ DTT) for $1 \mathrm{~h}(1 \mathrm{~h})$ at $27^{\circ} \mathrm{C}$. When required, divalent metal ions (2.5 $\mathrm{mM} \mathrm{CaCl}_{2}$, or $2.5 \mathrm{mM} \mathrm{MnCl}_{2}$, or $10 \mathrm{mM} \mathrm{MgCl}_{2}$ ) or the $\mathrm{Mg}$ chelating agent EDTA $(100 \mathrm{mM})$ were added prior to addition of the radiolabeled RNA. For time-course experiments, reactions were stopped after several minutes (1-30 $\mathrm{min}$ ) by addition of phenol-chloroform and extracted RNA was examined by $15 \%$ ureaPAGE analysis.

\section{Biophysical studies}

Sedimentation velocity experiments (Plateforme Biophysique, Partnership for Structural Biology) were done on an analytical ultracentrifuge XLI (Beckman Coulter) with a rotor speed of 42,000 rpm, at $4^{\circ} \mathrm{C}$, using a rotor Anti-60, and double-sector cells of optical path length $12 \mathrm{~mm}$ with Sapphire windows. Acquisitions were made using absorbance at $280 \mathrm{~nm}$ and interference optics. The reference is the buffer $(25 \mathrm{mM}$ MES, $150 \mathrm{mM} \mathrm{NaCl}$, and $5 \mathrm{mM}$ DTT [pH 6.0]) used for the sample. The analysis was done with the SEDFIT software, version $14.4 \mathrm{fb}$ and Gussi 1.0.8d.

The RNA-binding studies were carried out using fluorescence spectroscopy. Fluorescence emission measurements of $50 \mathrm{nM}$ fluorescently labeled RNA (5'-FAM-Ex-5-UAUACCUCUGCUUCUG $\left.\mathrm{CU}-3^{\prime}\right)$ with increasing concentrations of BmMael constructs were monitored at $25^{\circ} \mathrm{C}$ (excitation at $495 \mathrm{~nm}$ and emission at $515 \mathrm{~nm}$ ) in the reaction buffer containing $25 \mathrm{mM}$ MES ( $\mathrm{pH}$ 6.0), $150 \mathrm{mM} \mathrm{NaCl}, 5 \mathrm{mM}$ DTT, and $50 \mu \mathrm{M} \mathrm{ZnCl}_{2}$. The equilibrium dissociation constant $K_{\mathrm{D}}$ was determined by fitting the data using a nonlinear regression analysis (one site total binding) in Prism software.

\section{DATA DEPOSITION}

Structural coordinates are deposited within the Protein Data Bank under code no. 5AF0.

\section{ACKNOWLEDGMENTS}

We thank the High-throughput Crystallization facility in EMBL-Grenoble and the EMBL-ESRF Joint Structural Biology Group for access and support on the ESRF beamlines. We thank Joanna Kirkpatrick, Stefan Reich, and Le Roy Aline for help with experiments. E.C.'s stay in the laboratory was partly funded 
by the National Science Foundation International Research Experiences for Undergraduates program under grant no. CHE-1263336. We are grateful for fellowships from the EMBL Interdisciplinary Postdoc Programme (EIPOD) under Marie Curie COFUND Actions (K-M.C. and R.R.P), and European Molecular Biology Organization (EMBO) (R.R.P.). We acknowledge use of the Grenoble Instruct center (ISBG; UMS 3518 CNRS-CEA-UJF-EMBL) platforms supported by the French Infrastructure for Integrated Structural Biology Initiative FRISBI (ANR-10-INSB-05-02). This work was supported by grants from Fondation Recherche Médicale (DEP20131128529), Agence National de la Recherche (GuidedMethylation), and National Institutes of Health (1R01HD069592-01A1) to R.S.P. Work in the Pillai laboratory is supported by the EMBL.

Received January 9, 2015; accepted January 26, 2015.

\section{NOTE ADDED IN PROOF}

We note that the Lassa virus nucleoprotein (PDB: 4GV9), which is an active $3^{\prime}-5^{\prime}$ exoribonuclease, has both the ECHC and the DEDD motifs required for $\mathrm{Zn}$ and $\mathrm{Mn} / \mathrm{Mg}$ coordination, respectively. This again highlights the importance of DEDD motif for nuclease activity, as we showed here for the MAEL-domain protein from amoeba.

\section{REFERENCES}

Afonine PV, Grosse-Kunstleve RW, Echols N, Headd JJ, Moriarty NW, Mustyakimov M, Terwilliger TC, Urzhumtsev A, Zwart PH, Adams PD. 2012. Towards automated crystallographic structure refinement with phenix.refine. Acta Crystallogr D Biol Crystallogr 68: 352-367.

Bianchi ME, Agresti A. 2005. HMG proteins: dynamic players in gene regulation and differentiation. Curr Opin Genet Dev 15: 496-506.

Brennecke J, Aravin AA, Stark A, Dus M, Kellis M, Sachidanandam R, Hannon GJ. 2007. Discrete small RNA-generating loci as master regulators of transposon activity in Drosophila. Cell 128: 1089-1103.

Castaneda J, Genzor P, van der Heijden GW, Sarkeshik A, Yates JR III, Ingolia NT, Bortvin A. 2014. Reduced pachytene piRNAs and translation underlie spermiogenic arrest in Maelstrom mutant mice. EMBO J 33: 1999-2019.

Chen VB, Arendall WB III, Headd JJ, Keedy DA, Immormino RM, Kapral GJ, Murray LW, Richardson JS, Richardson DC. 2010. MolProbity: all-atom structure validation for macromolecular crystallography. Acta Crystallogr D Biol Crystallogr 66: 12-21.

Cowtan K. 2006. The Buccaneer software for automated model building. 1. Tracing protein chains. Acta Crystallogr D Biol Crystallogr 62: 1002-1011.

de Sanctis D, Beteva A, Caserotto H, Dobias F, Gabadinho J, Giraud T, Gobbo A, Guijarro M, Lentini M, Lavault B, et al. 2012. ID29: a high-intensity highly automated ESRF beamline for macromolecular crystallography experiments exploiting anomalous scattering. J Synchrotron Radiat 19: 455-461.

Emsley P, Lohkamp B, Scott WG, Cowtan K. 2010. Features and development of Coot. Acta Crystallogr Biol Crystallogr 66: 486-501.
Evans P. 2006. Scaling and assessment of data quality. Acta Crystallogr D Biol Crystallogr 62: 72-82.

Findley SD, Tamanaha M, Clegg NJ, Ruohola-Baker H. 2003. Maelstrom, a Drosophila spindle-class gene, encodes a protein that colocalizes with Vasa and RDE1/AGO1 homolog, Aubergine, in nuage. Development 130: 859-871.

Ghildiyal M, Zamore PD. 2009. Small silencing RNAs: an expanding universe. Nat Rev Genet 10: 94-108.

Hamdan S, Carr PD, Brown SE, Ollis DL, Dixon NE. 2002. Structural basis for proofreading during replication of the Escherichia coli chromosome. Structure 10: 535-546.

Kabsch W. 2010. XDS. Acta Crystallogr D Biol Crystallogr 66: 125-132.

Kawaoka S, Hayashi N, Suzuki Y, Abe H, Sugano S, Tomari Y, Shimada T, Katsuma S. 2009. The Bombyx ovary-derived cell line endogenously expresses PIWI/PIWI-interacting RNA complexes. RNA 15: $1258-1264$.

Lim AK, Kai T. 2007. Unique germ-line organelle, nuage, functions to repress selfish genetic elements in Drosophila melanogaster. Proc Natl Acad Sci 104: 6714-6719.

Malone CD, Hannon GJ. 2009. Small RNAs as guardians of the genome. Cell 136: 656-668.

McCoy AJ, Grosse-Kunstleve RW, Adams PD, Winn MD, Storoni LC, Read RJ. 2007. Phaser crystallographic software. J Appl Crystallogr 40: 658-674.

Murshudov GN, Skubák P, Lebedev AA, Pannu NS, Steiner RA, Nicholls RA, Winn MD, Long F, Vagin AA. 2011. REFMAC5 for the refinement of macromolecular crystal structures. Acta Crystallogr D Biol Crystallogr 67: 355-367.

Nurizzo D, Mairs T, Guijarro M, Rey V, Meyer J, Fajardo P, Chavanne J, Biasci JC, McSweeney S, Mitchell E. 2006. The ID23-1 structural biology beamline at the ESRF. J Synchrotron Radiat 13: 227-238.

Pek JW, Lim AK, Kai T. 2009. Drosophila maelstrom ensures proper germline stem cell lineage differentiation by repressing microRNA7. Dev Cell 17: 417-424.

Sato K, Nishida KM, Shibuya A, Siomi MC, Siomi H. 2011. Maelstrom coordinates microtubule organization during Drosophila oogenesis through interaction with components of the MTOC. Genes Dev 25: 2361-2373.

Sheldrick GM. 2010. Experimental phasing with SHELXC/D/E: combining chain tracing with density modification. Acta Crystallogr D Biol Crystallogr 66: 479-485.

Sienski G, Dönertas D, Brennecke J. 2012. Transcriptional silencing of transposons by Piwi and Maelstrom and its impact on chromatin state and gene expression. Cell 151: 964-980.

Skubak P, Pannu NS. 2013. Automatic protein structure solution from weak X-ray data. Nat Commun 4: 2777.

Soper SF, van der Heijden GW, Hardiman TC, Goodheart M, Martin SL, de Boer P, Bortvin A. 2008. Mouse maelstrom, a component of nuage, is essential for spermatogenesis and transposon repression in meiosis. Dev Cell 15: 285-297.

Xiol J, Spinelli P, Laussmann MA, Homolka D, Yang Z, Cora E, Couté Y, Conn S, Kadlec J, Sachidanandam R, et al. 2014. RNA clamping by Vasa assembles a piRNA amplifier complex on transposon transcripts. Cell 157: 1698-1711.

Zhang D, Xiong H, Shan J, Xia X, Trudeau VL. 2008. Functional insight into Maelstrom in the germline piRNA pathway: a unique domain homologous to the DnaQ-H $3^{\prime}-5^{\prime}$ exonuclease, its lineage-specific expansion/loss and evolutionarily active site switch. Biol Direct 3: 48 . 

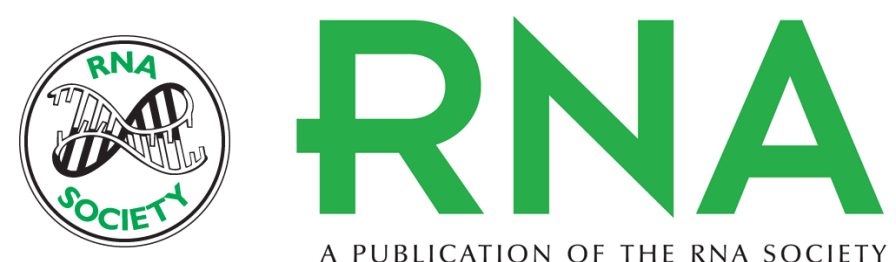

A PUBLICATION OF THE RNA SOCIETY

\section{Metazoan Maelstrom is an RNA-binding protein that has evolved from an ancient nuclease active in protists}

Kuan-Ming Chen, Edgar Campbell, Radha Raman Pandey, et al.

RNA 2015 21: 833-839 originally published online March 16, 2015

Access the most recent version at doi:10.1261/rna.049437.114

\section{References This article cites 27 articles, 5 of which can be accessed free at:} http://rnajournal.cshlp.org/content/21/5/833.full.html\#ref-list-1

Open Access Freely available online through the RNA Open Access option.

Creative This article, published in $R N A$, is available under a Creative Commons License

Commons (Attribution 4.0 International), as described at

License http://creativecommons.org/licenses/by/4.0/. Email Alerting $\begin{aligned} & \text { Receive free email alerts when new articles cite this article - sign up in the box at the } \\ & \text { Service }\end{aligned}$ top right corner of the article or click here. 